\title{
Experience from clinical genetics in hypertrophic cardiomyopathy: proposal for new diagnostic criteria in adult members of affected families
}

\author{
William J McKenna, Paolo Spirito, Michel Desnos, Olivier Dubourg, Michel Komajda
}

\begin{abstract}
Department of Cardiological

Sciences, St George's

Hospital Medical

School, London

W J McKenna

Dipartimento de

Cardiologia, Ospedale

Galliera, Genoa, Italy

P Spirito

Service de

Cardiologie, Hopital

Boucicaut, Paris,

France

M Desnos

Service de

Cardiologie, Hopital

Ambroise Paré,

Boulogne-Billancourt,

France

O Dubourg

Service de

Cardiologie, CHU

Pitie-Salpétrière,

Paris, France

M Komajda

Presented on behalf of causes of left ventricular hypertrophy are absent. In recent years, however, the systematic evaluation of pedigrees performed in the context of molecular genetic studies revealed that in some families with hypertrophic cardiomyopathy up to $20 \%$ of adults who carry a disease causing gene defect do not fulfil conventional echocardiographic criteria. None the less, most of these individuals show symptoms, electrocardiographic alterations, and/or minor echocardiographic abnormalities. Revised diagnostic criteria in members of families with hypertrophic cardiomyopathy are proposed, including major and minor criteria based on symptoms, and electrocardiographic and echocardiographic abnormalities. Given that the chance of inheriting the gene defect is $1: 2$, the likelihood that symptoms plus electrocardiographic or echocardiographic abnormalities are the expression of a disease causing gene is high.
\end{abstract} BIOMED1 (Contract

Number BMH1-

CT93-1788).

Participants:

W J McKenna (St

George's Hospital

Medical School,

London), P Spirito

(Ospedale Galliera,

Genoa), M Komajda

(CHU Pitie-Salpétrière,

Paris), K Schwartz

(INSERM UR 153,

Institut de Myologie

Paris), D Coviello

(Istituto di Biologia e

Genetica, Universita di

Genova, Genoa), H-P

Vosberg (Max-Planck-

Institut, fur

physiologische und

klinische Forschung, Abt.

Experimentalle

Kardiologie, Bad

Nauheim)

Correspondence to:

Dr W I McKenna,

Department of Cardiological

Sciences, St George's

Hospital Medical School,

Cranmer Terrace, London

SW17 0RE.

Accepted for publication

15 October 1996

\section{Summary}

The diagnosis of hypertrophic cardiomyopathy has relied on echocardiographic demonstration of unexplained left ventricular hypertrophy. The prevalence of hypertrophic cardiomyopathy defined in this way has been estimated to be 1:500 and experience indicates that these criteria are relatively specific when other

(Heart 1997;77:130-132)

Keywords: familial hypertrophic cardiomyopathy; diagnostic criteria

Hypertrophic cardiomyopathy is currently defined as a heart muscle disorder which is characterised by unexplained ventricular hypertrophy. ${ }^{1}$ The disease is usually familia with autosomal dominant inheritance. It has been considered to be rare; however, recent reliable clinical studies indicate a prevalence of at least $1: 500 .^{2}$ The diagnostic criteria for the disease have evolved largely as a function of the technology available. In the $1960 \mathrm{~s}$, reliance on the stethoscope and cardiac catheterisation emphasised the obstructive nature of hypertrophic cardiomyopathy. ${ }^{4}$ In the 1970s, the development of $M$ mode echocardiography, a technology that could image the anterior septum and posterior free wall, focused attention on the asymmetric distribution of hypertrophy, ${ }^{5}$ a morphological feature already reported in Teare's original description of the disease.$^{6}$ In the early 1980 s, cross sectional echocardiographic imaging of the whole heart led to the recognition that hypertrophy could also involve, or be confined to, ventricular segments other than the anterior septum..$^{78}$ At present, the diagnosis of hypertrophic cardiomyopathy relies mainly on the cross sectional echocardiographic demonstration of unexplained left ventricular hypertrophy. Because accurate quantitative diagnostic criteria are not available the diagnosis is often difficult and uncertain. In recent years mutations in the genes encoding contractile proteins have been identified as the cause of hypertrophic cardiomyopathy. ${ }^{9}$ It is, therefore, likely that molecular genetic techniques and criteria will ultimately become the tools for diagnosis and classification of this disease.

This evolution of the diagnostic criteria, which has been closely linked to technological advances, has resulted in the recognition of increasingly diverse morphological and functional manifestations of hypertrophic cardiomyopathy. In addition, pedigree analysis has revealed that individuals who carry the defective gene may not fulfil the echocardiographic diagnostic criterion of unexplained left ventricular hypertrophy and may show only mild echocardiographic and/or electrocardiographic abnormalities. ${ }^{10-13}$

Because familial hypertrophic cardiomyopathy has an autosomal dominant pattern of inheritance, the probability of disease in first degree relatives is $50 \%$ and within an affected family the likelihood that minor electrocardiographic or echocardiographic abnormalities represent the expression of disease is much greater than it would be outside the context of familial disease. It is uncertain whether subjects with these mild morphological alterations are at significant risk of developing important clinical manifestations of the disease. Sudden death, supraventricular and ventricular tachycardias, and embolic cerebrovascular accidents have been documented in such individuals. ${ }^{101114}$ The distinction between affected and non-affected members is also important for pedigree analysis and family counselling and for genetic analyses aimed at identifying linkage to a particular chromosomal locus.

Based on the premise that in the context of familial disease otherwise unexplained mild echocardiographic or electrocardiographic abnormalities will have a high probability of being the expression of a gene abnormality, we propose that the diagnosis of hypertrophic car- 
Table of criteria

\begin{tabular}{|c|c|}
\hline Major criteria & Minor criteria \\
\hline \multicolumn{2}{|c|}{ Echocardiography } \\
\hline $\begin{array}{l}\text { Left ventricular wall thickness } \geqslant 13 \mathrm{~mm} \\
\text { in the anterior septum or posterior wall or } \\
\geqslant 15 \mathrm{~mm} \text { in the posterior septum or free wall }\end{array}$ & $\begin{array}{l}\text { Left ventricular wall thickness of } 12 \mathrm{~mm} \text { in } \\
\text { the anterior septum or posterior wall or of } \\
14 \mathrm{~mm} \text { in the posterior septum or free wall. }\end{array}$ \\
\hline \multirow[t]{2}{*}{ Severe SAM (septal-leaflet contact) } & Moderate SAM (no leaflet-septal contact). \\
\hline & Redundant MV leaflets. \\
\hline \multicolumn{2}{|c|}{ Electrocardiography ${ }^{15}$} \\
\hline LVH + repolarisation changes (Romhilt \& Estes) & $\begin{array}{l}\text { Complete BBB or (minor) interventricular } \\
\text { conduction defect (in LV leads) }\end{array}$ \\
\hline \multirow{2}{*}{$\begin{array}{l}\text { T wave inversion in leads I and aVL }(\geqslant 3 \mathrm{~mm}) \\
\left.\text { (with } \mathrm{QRS}-\mathrm{T} \text { wave axis difference } \geqslant 30^{\circ}\right), \\
\mathrm{V} 3-\mathrm{V} 6(\geqslant 3 \mathrm{~mm}) \text { or II and III and } \mathrm{aVF}(\geqslant 5 \mathrm{~mm})\end{array}$} & Minor repolarisation changes in LV leads \\
\hline & Deep S V2 (> 25 mm) \\
\hline $\begin{array}{l}\text { Abnormal } \mathrm{Q}(>40 \mathrm{~ms} \text { or }>25 \% \mathrm{R} \text { wave) in at } \\
\text { least } 2 \text { leads from II, III, aVF (in absence of left } \\
\text { anterior hemiblock), V1-V4; or I, aV1, V5-V6 }\end{array}$ & $\begin{array}{l}\text { Unexplained chest pain, dyspnoea or } \\
\text { syncope }\end{array}$ \\
\hline
\end{tabular}

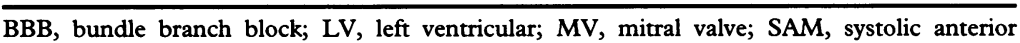
motion of the mitral valve.

diomyopathy in a first degree adult relative of patients with hypertrophic cardiomyopathy would be fulfilled by the presence of:

- One major criterion, or

- Two minor echocardiographic criteria, or

- One minor echocardiographic plus two minor electrocardiographic criteria.

We emphasise that the diagnosis of hypertrophic cardiomyopathy in the presence of other potential causes of left ventricular hypertrophy (such as athletic training, systemic arterial hypertension, or obesity) remains problematic and must be considered outside the boundaries of the present article. In addition the disease may not become expressed until after adolescent growth is completed. ${ }^{16}$ Therefore, the proposed criteria cannot be applied to children and adolescents. Diagnostic criteria in those under 10 years of age would require a body surface area corrected left ventricular wall thickness of $>10$ $\mathrm{mm}$; this provides a specific diagnostic criterion but the absence of such a feature does not exclude disease.

\section{Echocardiographic criteria}

Cross sectional echocardiographic measurements of left ventricular wall thickness are obtained at end diastole, primarily from the parasternal short-axis planes; the parasternal long-axis and apical views are also used to integrate the observations obtained from the short-axis views. In the parasternal short-axis plane, the left ventricle is divided into four segments that identify the anterior and posterior portions of the ventricular septum, and the lateral and infero-posterior left ventricular free walls. ${ }^{1718}$ Wall thickness is measured at the levels of both the mitral valve and the papillary muscles in each of these four ventricular segments. Because the resolution of the ultrasound beam is lower in the segments that are not perpendicular to the beam-that is, the posterior septum and lateral free wall, the wall thickness values required for diagnosis of left ventricular hypertrophy in these segments are higher than those used for the posterior septum and lateral free wall.

Left ventricular wall thickness measurements are influenced by variables such as gen- der, body size, and left ventricular diastolic cavity dimension. It is beyond the scope of this article to provide correction values for these variables. Nevertheless it is important to emphasise that, for example, a left ventricular wall thickness of $12 \mathrm{~mm}$ would have a higher diagnostic power in a woman $160 \mathrm{~cm}$ in height and with a left ventricular diastolic cavity size of $<45 \mathrm{~mm}$ than in a man $180 \mathrm{~cm}$ in height and with a cavity size of $55 \mathrm{~mm}$.

Hypertrophy may be confined to the distal portion of the left ventricle in some subjects. Measurements of wall thickness in the distal left ventricle are less accurate than those obtained in the proximal portion, since the ultrasound beam is not perpendicular to the distal segments of the septum or the free wall. Therefore, determination of wall thickness in the apical portion of the ventricle relies on a qualitative rather than a quantitative assessment.

Abnormalities of the mitral valve apparatus, with particularly long and redundant valve leaflets, have been described in patients with hypertrophic cardiomyopathy. ${ }^{19}$ Affected family members may show redundant mitral valve leaflets with or without mild-to-moderate systolic anterior motion (SAM) of the leaflets. This echocardiographic feature can be considered a minor criterion for diagnosis in a family member and can be used for diagnosis in association with other minor criteria.

Systolic anterior motion of the mitral valve should be assessed according to established criteria and defined as being severe in the presence of anterior mitral leaflet-septal contact, or moderate in the absence of leaflet-septal contact. ${ }^{20}$

\section{Electrocardiographic criteria}

In some family members with genetically confirmed hypertrophic cardiomyopathy, echocardiographic studies are normal and electrocardiographic abnormalities may be the only clinical expression of the disease. It is proposed that a single major electrocardiographic criterion shown in the table is indicative of disease. This is based on observations in patients who are gene carriers but do not fulfil echocardiographic diagnostic criteria. ${ }^{10-1321}$ Such abnormalities include left ventricular hypertrophy with repolarisation changes, isolated repolarisation changes with moderate to severe $T$ wave inversion, and deep $Q$ waves among the major criteria, because these electrocardiographic alterations are seldom present in the absence of obvious cardiovascular disease whereas they are the most common electrocardiographic abnormalities in family members who carry the defective gene but do not have echocardiographic alterations characteristic of hypertrophic cardiomyopathy. ${ }^{10-13}{ }^{22}$ Conversely, minor left ventricular interventricular conduction defects or repolarisation changes and a deep $S$ wave in lead V2 are included among the minor electrocardiographic criteria, because these abnormalities, while not uncommon in hypertrophic cardiomyopathy, may also be found in the normal 
population in the absence of significant cardiovascular disease. Complete left or right bundle branch block are uncommon in the absence of other echocardiographic or electrocardiographic features of hypertrophic cardiomyopathy. In addition, they may be found in the absence of other evidence of cardiovascular disease, particularly in the elderly.

Symptoms of chest pain (rest or exertional), disproportionate dyspnoea on exertion, or exertion-related syncope may be important markers of disease in the young, but will be less so in the older patients where the likelihood of other, though perhaps unrecognised, cardiovascular disease will be greater.

The above criteria for diagnosis of hypertrophic cardiomyopathy in members of affected families are presented as a working framework to improve diagnostic accuracy and understanding of the broad spectrum of the disease. It is recognised that penetrance of the disease is occasionally incomplete and some genetically affected adults have a normal ECG and cross sectional echocardiogram. In addition, fulfilment of these criteria does not necessarily imply exposure to the risks and limitations known to be associated with hypertrophic cardiomyopathy. Long term follow up studies of this emerging population of 'healthy' carriers of the genetic abnormality will be needed to clarify the natural history of this apparently less severe expression of the clinical disease spectrum.

Dr Spirito is supported by Telethon-Italia grants 600 and $860 \mathrm{c}$.

1 Richardson P, McKenna W, Bristow M, Maisch B Mautner B, O'Connell J, et al. Report of the 1995 World Health Organization/International Society and Federation of Cardiology Task Force on the Definition and Classification of Cardiomyopathies. Circulation 1996 93:841-2.

2 Maron BJ, Peterson EE, Maron MS, Peterson JE. Prevalence of hypertrophic cardiomyopathy in an outpatient population referred for echocardiographic study. Am $\mathcal{F}$ Cardiol 1994;73:577-80.

3 Maron BJ, Gardin JM, Flack JM, Gidding SS, Kurosaki TT, Bild DE. Prevalence of hypertrophic cardiomyopathy in a general population of young adults. Echocardiographic analysis of 4111 subjects in the CARDIA Study. Coronary Artery Risk Development in (Young) Study. Coronary Artery Risk Dev.

4 Wigle ED, Auger P, Marquis Y. Muscular subaortic stenosis. The direct relation between the intraventricular pressis. The direct relation between the intraventricular pres-
sure difference and the left ventricular ejection time. Circulation 1967;36:36-44.
5 Maron BJ, Epstein SE. Hypertrophic cardiomyopathy: discussion of nomenclature. Am f Cardiol 1979;43: $1242-4$

6 Teare D. Asymmetrical hypertrophy of the heart in young adults. Br Heart $\mathcal{F} 1958 ; 20: 1-8$.

7 Maron BJ, Gottdiener JS, Epstein SE. Patterns and significance of distribution of left ventricular hypertrophy in hypertrophic cardiomyopathy. A wide angle, two dimenhypertrophic cardiomyopathy. A wide angle, two dimen-
sional echocardiographic study of 125 patients. $A m \mathcal{F}$ Cardiol 1981;48:418-28.

8 Shapiro LM, McKenna WJ. Distribution of left ventricular hypertrophy in hypertrophic cardiomyopathy: a twohypertrophy in hypertrophic cardiomyopathy: a two-
dimensional echocardiographic study. $\mathcal{f}$ Am Coll Cardiol dimensional ech

9 Schwartz K, Carrier L, Guicheney P, Komajda $M$ Molecular basis of familial cardiomyopathies. Circulation 1995;91:532-40.

10 McKenna WJ, Stewart JT, Nihoyannopoulos P, McGinty F, Davies MJ. Hypertrophic cardiomyopathy without hypertrophy: two families with myocardial disarray in the absence of increased myocardial mass. Br Heart $\mathcal{f} 1990$; 63:287-90.

11 Watkins H, McKenna WJ, Thierfelder L, Suk HJ, Anan R, O'Donoghue A, et al. Mutations in the genes for cardiac troponin $\mathrm{T}$ and alpha-tropomyosin in hypertrophic cardiomyopathy. N Engl f Med 1995;332:1058-64

12 Thierfelder L, MacRae C, Watkins H, Tomfohrde J, Williams M, McKenna W, et al. A familial hypertrophic cardiomyopathy locus maps to chromosome 15q2. Proc Natl Acad Sci U S A 1993;90:6270-4.

13 Epstein ND, Cohn GM, Cyran F, Fananapazir L. Differences in clinical expression of hypertrophic cardiomyopathy associated with two distinct mutations in the beta-myosin heavy chain gene. A $908 \mathrm{Leu}-\mathrm{Val}$ mutathe beta-myosin heavy chain gene. A 908Leu-Val muta-
tion and a 403Arg-Gln mutation. Circulation 1992;86: tion and

14 Maron BJ, Kragel AH, Roberts WC. Sudden death in hypertrophic cardiomyopathy with normal left ventricular mass. Br Heart $\mathcal{F} 1990 ; 63: 308-10$.

15 Surawicz B, Uhley H, Borun R, Laks M, Crevasse L, Rosen $\mathrm{K}$, et al. The quest for optimal electrocardiography. Task Force I: standardization of terminology and interpretation. $A m \mathcal{F}$ Cardiol 1978;41:130-45.

16 Maron BJ, Spirito P, Wesley Y, Arce J. Development and progression of left ventricular hypertrophy in children with hypertrophic cardiomyopathy. $N$ Engl f Med 1986; 315:610-4

17 Spirito P, Bellotti P, Chiarella F, Domenicucci S, Sementa $A$, Vecchio C. Prognostic significance and natural history of left ventricular thrombi in patients with acute anterior of left ventricular thrombi in patients with acute anterior myocardial infarction: a two-dimensional

18 Spirito P, Maron BJ. Relation between extent of left ventricular hypertrophy and age in hypertrophic cardiomytricular hypertrophy and age in hypertro
opathy. $\Im$ Am Coll Cardiol 1989;13:820-3.

19 Klues HG, Proschan MA, Dollar AL, Spirito P, Roberts WC, Maron BJ. Echocardiographic assessment of mitral valve size in obstructive hypertrophic cardiomyopathy. Anatomic validation from mitral valve specimen. Circulation 1993;88:548-55.

20 Pollick C, Morgan CD, Gilbert BW, Rakowski H, Wigle ED. Muscular subaortic stenosis: the temporal relationship between systolic anterior motion of the anterior mitral leaflet and the pressure gradient. Circulation 1982; 66:1087-94.

21 Al-Mahdawi S, Chamberlain S, Cleland J, Nihoyannopoulos $\mathrm{P}$, Gilligan D, French $\mathrm{J}$, et al. Identification of a mutation in the beta cardiac myosin heavy chain gene in a family with hypertrophic cardiomyopathy. $\mathrm{Br}$ Hear $\mathcal{f} 1993 ; 69: 136-41$.

22 Dubourg $O$, Isnard R, Hagege A, Jondeau G, Desnos $M$, Sacrez A, et al. Doppler echocardiography in familial Sacrez A, et al. Doppler echocardiography in familial hypertrophic cardiomyopathy: the French
study. Echocardiography 1995;12:235-41. 